\title{
A Financial Theory Perspective of the Metrics Employed to Measure Value in the "Value in Healthcare" Methodologies
}

\author{
José Miguel Pinto dos Santos ${ }^{a}$ Sandra Bernardes de Oliveira ${ }^{b}$ \\ ${ }^{a}$ Department of Economics and Finance, AESE Business School, Lisbon, Portugal; ${ }^{b}$ Department of Social and \\ Organizational Sciences, Polytechnic Institute of Santarém, Santarém, Portugal and Centre for Health Studies and \\ Research, University of Coimbra, Santarém, Portugal
}

\section{Keywords}

Value in healthcare · Financial theory - Cost-benefit analysis . Cost-effectiveness analysis · Porter framework

\begin{abstract}
Background: Value in healthcare is becoming an important paradigm in the drafting of health policies, the management of healthcare institutions, the financing of healthcare provision, and the choice of technologies in healthcare delivery. Several different metrics have been proposed and are currently used by academics and practitioners in this field. Summary: There are many challenges, both ethical and methodological, in the attempt to measure value in healthcare. One arises from the close relationship between health and life. Although it is generally regarded that human life should not be subject to monetary valuation, several human activities, namely work, are currently valued. This allows for the valuation of health as it impacts on these human activities. Other challenges are measuring health benefits and costs. Several metrics have been proposed in the literature and are used in practice. The purpose of this paper is to appraise, from the perspective of modern financial theory, several metrics used for determining value in healthcare. Key Messages: Most metrics used to determine value in healthcare do not reflect
\end{abstract}

the concept of value used in modern financial theory. They rely mostly on accounting concepts such as costs, not in a prospective cash-flow perspective. Some adjustments need to be made to bring them into step with the financial theory of value.

(c) 2021 The Author(s). Published by S. Karger AG, Basel on behalf of NOVA National School of Public Health

\section{Uma perspetiva da Teoria Financeira sobre as métricas usadas para medir valor nas metodologias em 'Valor em Saúde'}

\section{Palavras Chave \\ Valor em saúde · Teoria financeira · Análise custo-benefício · Análise custo-efetividade · Modelo de Porter}

\section{Resumo}

Motivação: Valor em saúde é um paradigma cada vez mais usado na elaboração de políticas de saúde, na gestão de instituições de saúde, no financiamento de serviços de saúde e na escolha de tecnologias de tratamento. Várias métricas foram propostas e são usadas por académicos e profissionais. Sumário: A medição do valor da saúde apre- (c) 2021 The Author(s). Published by S. Karger AG, Basel on behalf of NOVA National School of Public Health

This article is licensed under the Creative Commons AttributionNonCommercial-NoDerivatives 4.0 International License (CC BYNC-ND) (http://www.karger.com/Services/OpenAccessLicense) Usage and distribution for commercial purposes as well as any distribution of modified material requires written permission.
José Miguel Pinto dos Santos

Department of Economics and Finance, AESE Business School Calçada Palma de Baixo 12

PT-1600-177 Lisboa (Portugal)

jmps@aese.pt 
senta várias dificuldades éticas e metodológicas. Embora usualmente se considere que que a vida humana não deve ser sujeita a avaliação monetária, várias atividades humanas, nomeadamente o trabalho, são passiveis de ser avaliadas em termos financeiros. Isto permite estimar o valor da saúde na medida em que a saúde tem impacto nessas atividades. No entanto existem outros desafios, tais como medir os custos e benefícios associados à saúde. Várias métricas para estimar valor em saúde foram propostas na literatura académica e são usadas na prática. $\mathrm{O}$ objetivo deste artigo é apresentar uma apreciação critica, feita do ponto de vista da teoria financeira, de várias dessas métricas. Mensagem principal: Muitas das métricas usadas em valor em saúde não refletem o conceito de valor que está na base da moderna teoria financeira: baseiam-se em conceitos contabilísticos, como custos, e não em cash-flows expectáveis no futuro. Para os tornar coerentes com a teoria de valor que é atualmente aceite necessitam de ser revistos.

() 2021 The Author(s). Published by S. Karger AG, Basel on behalf of NOVA National School of Public Health

\section{Introduction}

Healthcare systems are undergoing drastic changes in care management and delivery $[1,2]$. These changes are being driven by progress in medical technologies and procedures, the shift in the epidemiologic paradigm, the transformation of the demographic profile of populations, and the emergence of new budgetary constraints. As a consequence, policy-makers are increasingly aware of the importance of identifying interventions that provide the best health outcomes for the resources invested.

Health care organizations also strive to close the gap between their mission statements and their operations through a continuous search for improvements in managerial systems and changes in organizational structures and processes [3]. One of the emergent value propositions is being generated and developed in a new multidisciplinary field of research and practice known as valuebased healthcare $[1,4]$.

Value-based health care proposes a continuous cycle of improving quality of care, better cost control, and the introduction of new systems of financing and reimbursement for providers as substitutes for the prevalent fee-forservice [4-7]. Consumers and payers have become aware of the financial and health benefits to be obtained from value-based healthcare, while providers are striving for and achieving new levels of productivity and quality [8].
The concept of value has come to mean different things to different researchers and practitioners in the healthcare sector. Value may reflect clinical and health-related quality-of-life components as well as economic and social aspects. Despite the variety of definitions of value in healthcare, most conceptions of value in this field postulate that value is a function of outcomes achieved in relation to costs incurred $[2,6,7,9]$. Therefore, similarly to other economic endeavors, value in healthcare is created by the improvement of desired outcomes and/or cost reduction. Although cost measurement in the healthcare sector has all the complexity of costing found in any other industry, the real complexity is in measuring the benefits $[10,11]$. This is because benefits are closely related to individual preferences and these are heterogeneous, as can be confirmed not only in the literature but also in everyday life $[11,12]$.

However, the following question should be asked: Can we make human health equivalent to a monetary sum? The answer to this question from most thinkers in almost all cultural settings is "No." This negative answer does not preclude some aspects of human life, including healing and health improvements, from being evaluated monetarily, or the development of other nonmonetary measures.

A widely acceptable definition of value would therefore be helpful, if not indispensable, to achieve the intended benefits of value-based healthcare management and allow more accurate comparisons, either over time or between the outcomes of different healthcare organizations. This is important because even if two healthcare organizations have the same level of production for a medical procedure at the same cost, but one of them is able to achieve better functional outcomes (e.g., a lower rate of readmission after a surgical procedure), the one with better functional outcomes creates more value [13].

Although value in healthcare is a broad field with many ramifications, the aim of this paper is quite narrow. Its purpose is to draw attention to the fact that most of the value metrics mentioned in the healthcare literature do not reflect, and are at variance with, the concept of value used in modern financial theory. In modern financial theory, the value of an asset is considered to be a function of what may be expected to be obtained from that asset in the future, where the outcome is usually measured in cash terms [14-17]. However, most of the metrics used to determine value in healthcare seem to reflect different concepts of value from the current standard principles of modern financial theory. Some seek to value health by using ratios, which may indeed provide useful informa- 
tion on the efficiency of a health technology, but do not provide a measure of value. Others attempt to value health in monetary terms, with recourse to accounting concepts such as benefits and costs, which may not have direct correspondence with the ultimate reality check, namely cash flow $[18,19]$. This suggests that there is scope for the review and improvement of current metrics and the development of new metrics to determine value in healthcare methodologies, so as to better estimate and measure value creation in healthcare, through progress in medical technologies and procedures improvements in managerial systems, or changes in organizational structures and processes. Such a review and improvement are, however, beyond the scope of this paper.

In what follows, we start with some introductory remarks on the value of human health and human life. The concept of value employed in modern financial theory is then presented. Finally, a brief review is made of several methodologies for measuring value in healthcare and widely used by both academics and practitioners, namely, cost/benefit analysis, cost-effectiveness analysis (CEA), cost-utility analysis, quality-adjusted life years (QALY), and the Porter framework, in the light of the modern financial theory concept of value.

\section{The Value of Human Health}

\section{An Historical and Intercultural Perspective}

The concepts of health and life, albeit different, are so closely interrelated that they are sometimes used interchangeably. Illness is generally considered to impair [20] or subtract from life in some way, and this idea has found its way into modern metrics like QALY; over a certain time span, the greater a person's wellness and, correspondingly, the less illness, the greater the QALY assigned to that person during this period [21]. However, the close association made between these two concepts may sometimes cause confusion about the real meaning of value in health.

It has been a constant in human thought, if not actual practice, that the value of a human life should be considered immeasurable. This means that no proper equivalent to human life can be found in money or wealth. This idea is rooted in the concept that human beings are ontologically superior to all other earthly goods, animals, or things. We find this idea in Plato (428/7-348/7) when he makes the Athenian say in Laws (Book IX, 870) that "riches are for the sake of the body as the body is for the sake of the soul" [22]. He explains: "They [body and soul] are good, and wealth is intended by nature to be for the sake of them, and it is therefore inferior to them both, and third in order of excellence."

Plato establishes a clear hierarchy here, distinguishing three levels of existence that are not mutually comparable. The first and most precious is intellectual and moral life, the life of the soul, which is superior to the life of the body. This idea is not unique to Greek philosophy but can be found also in Judeo-Christian religious and philosophical thought, Chinese and Japanese political and moral philosophy, and elsewhere $[23,24]$. It is found, for example, in the writings of Fukuzawa Yukichi (1835-1901) when he explains that to call human beings "of all creatures ... the most highly endowed" [...] means that if they cultivate virtue by following the way of Heaven, enlarge their minds with knowledge and experience appropriate to human beings, touch things around them and associate with people, strive for their own independence, [...] then, and only then, can they be called "of all creatures ... the most highly endowed" [25]. The implication of this hierarchy is that the value of an honest, moral life cannot be compared with the value of the life of the body. That is, bodily life is not worth treachery, covetousness, or any other moral failings and weaknesses, so much so that a morally upright life in a sickly body is incomparably superior to a morally compromised life in a healthy body.

Second comes human bodily life, which is superior to any kind of riches, material goods, or money, and thus should not be subject to comparison with any of them. This idea that a person, and his/her life, is not measurable in monetary units is also almost universal. The concept that one human life is worth no less than another human life is perhaps most famously expressed in the well-known words from Exodus (21:23-24) "A life for a life, an eye for an eye, a tooth for a tooth," but this equivalence has been widely found in most cultural settings throughout history and is reflected in criminal law and societal rules, as amply demonstrated in anthropological research by Boas [26]. It is also found, in a counterintuitive way, in the intellectual attempts made throughout history to justify slavery; these always rely on the specious argument that slaves lack some human characteristic, making them less than fully human and thus passive to being evaluated monetarily and transacted in the marketplace $[27,28]$. Lastly, the economic and societal lockdown declared by many world governments in early 2020 shows that human life and human health continue to be widely regarded as being superior to any economic riches. That this idea remains deeply ingrained in our time is proved not only by the lockdowns themselves but also by the public 
statements made to justify their necessity, even at a very high economic cost, in order to save vulnerable lives at this time of a viral pandemic.

Therefore, as the life and the health of a person are intrinsically linked to each other and given the World Health Organization's definition of health as "a state of complete physical, mental, and social well-being and not merely the absence of disease or infirmity" [29], it may also be argued that a person's health should not be evaluated in monetary units. However, because resources are limited, and public policy entails making choices about the provision of healthcare, healthcare outcomes must be weighed against costs. As it is impossible to compare the magnitude (or impact) of one medical condition in a person's life (or health) to that of another medical condition in the "units" of one of them, e.g., the seriousness of a kidney condition versus the seriousness of a heart condition, it is sometimes practical to convert and measure both in monetary terms to allow comparisons to be made. Given that some kind of evaluation must be made, the question becomes: What is the most suitable methodology? We will see below that the main problem lies in developing a unit of measurement that can reflect individual perceptions and preferences as well as being congruent with the fundamental frameworks of the different fields of research and practice that deal with value in healthcare.

The attempt to value health, or the corresponding evaluation of disease, becomes more important, critical even, at a time when national health systems, notably those in developed countries, have faced various challenges, especially in the past two decades. These challenges, which policy-makers must address, include demographic changes, epidemiological transition (e.g., the complexity of patients, a decline in infectious diseases which, however, spread faster and become more global, and a growth in chronic noncommunicable diseases), and the introduction of new healthcare technologies (taken here to refer to all aspects of healthcare including diagnoses, therapies, surgeries, medications, and other related procedures. All of this is happening simultaneously with increasingly stringent financial constraints [30, 31].

In general, public opinion identifies the unprecedented ageing process in most developed countries as one of the main reasons for healthcare organizations' struggle to comply with financial constraints and still fulfil their mission, i.e., provide healthcare of value to patients. However, research demonstrates that new technologies could be the main cause of the expected increase in healthcare costs in the coming decades. Cost contention and innova-

A Financial Perspective of the Metrics Employed to Measure Value tions in treatment could become conflicting realities [32, 33].

At the macro-level, there is also a constant debate in many countries on the adequacy of health expenditure, whether it is too low or too high, when the GDP is taken into account. It is also very important to understand the extent to which additional healthcare expenditure yields patient benefits in the form of improved health outcomes [34]. At the micro-level, much progress has been made in the evaluation of the costs and benefits of individual technologies. New and previous frameworks of cost-effectiveness are frequently applied, in both theoretical studies and actual practice. In the past few years, systematic literature reviews have shown the growing interest in the subject [18]. But one question has never been raised: are these frameworks coherent with the modern theory of value?

\section{A Financial Theory Perspective}

There was a marked change in the concept of value in the late 19th century. Although perhaps a simplification of a complex history, it can be said that, from Aristotle to Adam Smith, David Ricardo and Karl Marx, the value of goods had long been considered dependent on the value of labor put into their production [35-37]. We can see here that the value of products was thus linked to one aspect of human life: work.

This view was superseded by the modern view, formalized by Fisher [38], widely used in modern financial theory and found in any contemporary textbook on the subject [14-17], which makes the value of any goods or assets equal to the current value of the future cash flow that is expected to accrue from it. Mathematically, this is expressed as:

$$
\text { Value }=\sum_{t=1}^{T} C F_{t} /(1+k)^{t} .
$$

In this equation, the expected future net cash flows $(C F)$ are discounted at the appropriate cost of capital $(k)$, and are summed over the expected life of the asset $(T)$ which, in some cases, may be considered infinite, to yield the Value of the asset. An expected cash flow may either be positive, in which case it adds to the value of the asset, or negative, which subtracts from its value. In turn, the cost of capital is a function of the risk for a future cash flow, which may take different forms. It may accrue through time as the asset is being used, i.e., by the sale of the products or services it produces. Or it may be the "opportunity costs" arising from one's own consumption of the products or services that the asset generates. Or, fi- 
nally, the cash flow may be constituted by the market price at which the asset may be expected to be sold in the present or at a future date.

The radical difference between these two theories of value, i.e., what is "value" and what gives value to an asset, should be stressed here for its important implications for the discussion below about the metrics used for determining value in healthcare. Whereas, according to the labor theory of value, the worth of an asset has been considered as a function of the labor added to it in the past up to the moment of evaluation, in modern financial theory, value is considered to be a function of what can be "extracted" from the asset in the future. Furthermore, the value of something according to the former theory may be estimated with a high degree of certainty because it was added to the asset in the past, but the estimation of the value of something according to the latter theory is inherently uncertain because it depends on the expectation of how much may be extracted from it in the future. Moreover, an evaluation of future cash flow involves a degree of subjectivity that is absent when evaluating the value of labor added to an asset in the past. According to modern economic theory, this subjectivity, allowing for different evaluations of the asset, is one of the main reasons for trading in assets; some agents are willing to buy because they evaluate the asset more highly than the asked price, while others are willing to sell because they evaluate it lower than the bidding price.

Associated with the modern financial theory of value, there is a set of valuation methods, known as discounted cash flow methods, which are commonly applied to all kinds of assets, from commodities to capital goods. But should these be applied when evaluating human life and human health? If it is held that neither human life nor health can be measured in monetary units, then these techniques are not applicable in the conception, drafting, and management of public-health policies.

However, even if these methods should not be used to evaluate human health, it may be argued that it is legitimate to use them to measure the value of certain human activities that are affected by and depend on an individual's state of healthiness, such as work and consumption. For instance, although not attempting to put a price tag on a heart or kidney condition, the consequences of such conditions on a person's ability to generate income may allow a monetary evaluation to be made of one of the impacts of the disease on an individual's health, e.g., their earning power. Something akin to this is already current practice in the courts which routinely establish compensation awards to victims of accidents based on the esti- mated loss of future earnings and future increased expenses. Furthermore, notwithstanding all possible ethical objections, the fact is that several metrics are already in current use to evaluate the cost-effectiveness or economic impact of alternative health policies at the macro-level and of healthcare procedures at the micro-level. In what follows, a first attempt is made to gauge the adherence of the metrics currently in greater use in health economics to the principles of modern financial theory.

\section{A Critique of the Metrics Used to Measure Value in Healthcare Methodologies}

Health authorities, policy-makers, and practitioners are constantly facing trade-offs in investment decisions. In the last decades, several metrics have emerged to support decision-making. These include attempts to measure the value of healthcare technologies [39-41]. Despite the progress made, many questions remain unanswered, and the quest for how to measure the value of investments in health continues $[21,41,42]$. Four of the most commonly used frameworks to gauge value in healthcare are examined below. The first, cost/benefit analysis, attempts to monetize value in healthcare but is difficult to apply in practice, despite its apparent simplicity. The second, CEA, evaluates alternative healthcare technologies by using a physical standard cogent to the health problem at hand, without attempting to monetize it. In the third, cost-utility analysis, the consequences of different healthcare alternatives under consideration are adjusted by using individual preferences. QALY attempts to quantify changes in expected life value arising from the use of different healthcare technologies. Finally, the Porter framework, which developed a well-based set of standards to measure the outcomes of different clinical conditions, relies on a methodology of cost measurement that is widely perceived to be cumbersome and heavy on administrative procedures, thus making it difficult to implement. As a result, it has only been adopted by a few healthcare organizations, and is generally only applied to a sector or department of that organization.

\section{Cost-Benefit Analysis}

In health economics, value is often described based on microeconomic principles, recognizing that it is best defined as what individuals would be willing to pay to acquire more healthcare. The proxy used for the willingness to pay is normally the market price. However, Arrow [43] stated that consumers in healthcare markets often de- 
mand medical care with very limited information on product characteristics and prices, and thus frequently rely on medical providers to act as their agents.

Cost-benefit analysis seeks to compare the benefits to be obtained from a certain medical procedure with the costs associated with the procedure over a relevant span of time. Both benefits and costs are measured in monetary terms, which may entail estimating years of life or improvements in health and well-being in monetary units. Alternatively, as suggested above, it may be used so that the benefits are not defined in terms of life-years or wellbeing, but rather the impact additional life-years or wellbeing have on some aspect of human activity, such as work and income-generating ability [41]. Although this may be applied at a micro-level to help in individual decision-making, it is most often used at the macro-level to evaluate the impact of a new health policy at the national or regional level. It involves identifying the costs, often not an easy task. Three types of costs associated with a medical decision may be considered: direct medical costs, direct nonmedical costs, and indirect costs. Direct medical costs include all those associated with the procedure. Direct nonmedical costs are costs such as transportation costs that are necessary for the patient to undergo the medical procedure. Indirect costs are opportunity costs associated with the procedure, one of the most cited examples being lost output during the time spent receiving healthcare. Cost/benefit analysis also involves the identification of benefits, e.g., the monetary value of the avoidance of lower production due to illness, the monetary value of the utility gained from an extended lifetime or better health during the remaining lifetime, or even future medical costs avoided due to prevention [41, 43, 44].

The value to be gained is measured by the following metric in cost/benefit analysis:

$$
\text { Value }=\sum_{t=1}^{T}\left(B_{t}-C_{t}\right) /(1+k)^{t} .
$$

In this metric, $B_{t}$ refers to the benefits originating at a certain time point $(t), C_{t}$ is the cost associated with them, and $k$ is the intertemporal discount rate. If the Value $>0$, then the policy measure or new technology should be used even if there are groups in society who will not benefit from it, as the imperative is generally to increase the social benefit.

Overall, this metric is congruent with modern financial theory. It evaluates the net benefits that a healthcare technology will generate in the future, discounted at an appropriate rate. The main potential criticism from a financial theory perspective is that costs and benefits are used instead of actual cash flows. For example, it is a common accounting practice to partition certain types of oneoff cash outflow, usually termed "capital expenditure" or "investment," into a number of yearly costs (or depreciation), thus resulting in an artificial reduction of the present value of that cash outflow and making the project appear better on paper. Other methodological problems must also be resolved. As already noted, although it may be difficult to make a direct evaluation of most of the benefit of increased wellness, some of the consequences, notably increased productivity, can be estimated.

The difficulty of assessing the value of benefits is another challenge. Benefits in healthcare are nontradable goods, and there is therefore usually no pricing. Market pricing is a source of real-world information concerning scarcity and preferences, which allows policy-makers to allocate resources efficiently. A frequently used methodology to overcome this problem is to deploy stated preference methods that elicit statements about preference from consumers, i.e., contingent valuation (CV). In this methodology, individuals are confronted with existing market-like situations and reveal their preferences in the contingent scenario presented for their consideration. For example, they may be asked how much they would each be willing to pay for a new HPV vaccine, conditional to the existence of a particular charging scheme [45]. In these studies, it is vital that the CV survey is behavioral in design, seeking to measure an intention to pay for a specific program with specific attributes in a clearly defined and realistic manner $[46,47]$. One of the critical elements is the type and quality of the questions in the survey. Unless correctly formulated, they may induce bias into the results. In these studies, the prices suggested by the respondents are always conditional to the constructed (hypothetical) market presented to them [48]. For instance, Johannesson and Jönsson [49], in their study of the different techniques available, concluded that discrete valuation questions work better than open-ended CV questions, notably because they provide some information about the price.

\section{Cost-Effectiveness Analysis}

CEA is an alternative methodology that avoids the difficulty of making a monetary evaluation of the benefits to be obtained from a medical procedure. CEA is most frequently employed when it is assumed that a certain medical objective is desirable. No attempt is made to evaluate the objective in monetary terms as the aim of the analysis is to compare the costs of alternative ways of achieving the objective. Therefore, CEA is employed by health 
economists to assess the value of medical care in order to identify the alternative that maximizes health gains, given the budget constraints. In other words, CEA seeks to evaluate how "the incremental cost of an intervention is related to the incremental health effect (where the intervention is compared to the most relevant intervention alternative)" [4].

CEA is usually expressed by the following ratio:

\section{CEA ratio $=$ incremental cost/incremental health effect.}

This ratio weights the costs of healthcare technologies to the final health outcome generated by the use of such technologies, i.e., an improvement in patient outcomes. CEA does not attempt to calculate the monetary value of the health outcome per se (e.g., life-years gained or the decrease in the number of years of disability), or the value of human activities that the outcome will make possible. Furthermore, CEA does not allow for comparisons between proposed improvements in different medical areas, e.g., a disease in the lungs versus a problem in the kidneys. This is an advantage, in that it avoids the thorny questions of measuring the benefits to be gained by addressing different health problems; however, it has the drawback of not providing the information necessary for making decisions at the macro-level in public-health policy.

From the financial theory perspective, CEA suffers from several problems. One is that it does not take the time span and pattern of the costs into account, but just sums them up, therefore ignoring the time value of money for the costs incurred. Another is that it takes a cost, rather than a cash flow, perspective, which opens the door to the inclusion of potentially irrelevant costs in the decision made, namely sunk costs and depreciation. Finally, it is not a measure of value but of efficiency, and a counterintuitive one, as increases in cost efficiency are expressed as decreasing CEA ratios.

\section{Cost-Utility Analysis}

The basic principle behind cost-utility analysis is that decisions made by individuals about additional healthcare should be compared with their "opportunity cost," i.e., in terms of which benefits, income, or other resources they are willing to forgo. The seminal work of Grossman $[50,51]$ on the demand for healthcare suggests that individuals invest in their own human capital by improving their physical capacity and increasing their stock of knowledge.
In his widely cited model, Grossman $[50,51]$ considers two possibilities: (1) healthcare as a stock, similar to human capital stock; and (2) health as a joint production process that, on the one hand, requires an individual contribution, i.e., the time to consume healthcare, and on the other, an investment in healthcare (health as a stock). The production of health is an investment that is expected to increase the health stock. The health stock is subject to depreciation, and the depreciation rate varies with the individual. Contrary to other capital stock goods, this depreciation rate has a stochastic nature, and the depreciation of the health stock may be uncertain in some periods since most of the disease episodes are unexpected.

Under utility theory, it can be stated that the individual chooses a lifestyle that contributes to increasing the stock of health capital, which means a decrease in the probability of becoming sick (e.g., knowing that the individual will have healthy meals lowers the probability of gastrointestinal cancer, exercise decreases the likelihood of cardiovascular diseases, and doing screening exams for the early detection of some diseases makes a cure more probable).

Preferences for healthcare are heterogeneous and different individuals attach different values to health outcomes. Two patients may value the same health gain differently, and although some of this difference may be related to income disparity, much of it arises from different preferences. There is also variation in the extent to which different individuals are willing to trade off an extension of their life expectancy with various aspects of their quality of life. This heterogeneity makes diverse subpopulations give a different evaluation of the health gain delivered by the same intervention [52]. The cost-utility approach is most usefully deployed to analyze the alternatives that can increase the number of years of life but at the cost of severe secondary effects [53].

From the perspective of financial theory, cost-utility analysis has a sound analytic framework, particularly when it attempts to measure costs on a cash flow basis, because it takes into account the revealed preferences of healthcare consumers and "time-weights" their benefits and opportunity costs by using an appropriate discount rate.

\section{QALY As a Utility Measure in Healthcare}

QALY is a metric commonly used to measure benefits in healthcare, especially within the cost-utility framework, and it represents the standard outcome used for the purpose of allocating resources across a healthcare system. Here, health gain is defined in terms of an interme- 
diate outcome measure (e.g., cholesterol reduction), a unidimensional measure of survival (e.g., life-years saved), or a measure that captures the trade-off between quality of life and survival $[54,55]$.

QALY is a measure of quality, including the quality and timespan or "quantity" of life. QALY can provide an indication of the benefits obtained from medical procedures in terms of quality of life and survival. Disabilityadjusted life-years are closely related health metrics that weight survival based on measures of disability [55]. Therefore, an intervention with a lower cost-to-QALY ratio would be preferred over an intervention with a higher ratio.

The value of a QALY gain can be calculated via "stated preference" or "revealed preference" methods. Revealed preference uses real-world behavior to infer the underlying value placed on QALY. Revealed preference is based on the assumption that prices in the marketplace reflect the preferences of consumers and patients. Thus, if we can determine how the price of treatment changes when it adds one more year to QALY, in theory we can determine the value of a QALY revealed by the marketplace. The use of the revealed preferences process relies on a set of market assumptions that could fail in the healthcare market $[55,56]$.

Although QALY can be adapted for individual decision-making, this is not how it is commonly used. There are significant limitations to the application of QALY because individuals with the same illness may have different preferences for what constitutes a state of health. For example, one individual with advanced cancer may prefer length of overall survival above all else whereas another might make minimizing symptoms a top priority [56].

\section{The Porter Framework}

The starting point of the Porter conceptual framework is the definition of value in healthcare. Value stands for the "health outcomes achieved which matter to patients relative to the cost of achieving those outcomes" [5]. Porter expresses this as follows:

$$
\text { Value }=\text { outcome/cost. }
$$

Outcomes are inherently condition-specific and multidimensional. For any medical condition, no single outcome captures the total results of care. Cost, the equation's denominator, refers to the total costs of the full cycle of care for a patient's medical condition, not the cost of the individual services. To lower cost, the best approach is often to spend more money on some services to reduce the need for others. So, in contrast to economic evaluation, cost is not expected to be lower on a single health outcome due to the multidimensional nature of the numerator of this equation.

The Porter framework takes account of the relationship between outcomes and costs, with the idea that providers should improve outcomes to maximize value while also seeking to maintain or decrease costs. Cost reduction without regard to the outcomes achieved is dangerous, leading to false "savings" and potentially limiting effective care $[5,6]$.

To measure value under this model, it is important to start by defining a specific disease or patient population. Second, care is organized over medical conditions and full care cycles. It considers the patient's initial diseases, diagnoses, reported health outcomes, patient satisfaction, and other clinical and administrative factors [5]. Probably the most important idea behind this framework is that organizations must focus on the costs of treating individual patients with specific medical conditions over their full cycle of care, rather than analyze costs at the specialty or service department level. Third, costs and outcomes must be quantitatively measured to assess value $[57,58]$.

The way to measure outcomes is relatively well established in the literature. Porter [5] maintained that "outcomes for any medical condition can be arrayed in a three-tiered hierarchy in which the top tier is generally the most important and lower-tier outcomes involve a progression of results contingent on success at the higher tiers." Tier 1 is the health status that is achieved, or, for patients with some degenerative conditions, retained. Tier 2 outcomes are related to the recovery process. Tier 3 is the sustainability of health.

Thus, the patient's perspective can provide important information to understand the outcomes achieved such as complications, pain, and a return to the activities of daily living. "If value improves, [then] patients, payers, providers, and suppliers can all benefit while the economic sustainability of the health care system increases" $[5,8]$.

The assessment of the denominator of Porter's value equation has received less attention, despite the fact that it could enable a truly structural cost reduction via steps such as reallocating spending, eliminating non-valueadding services, better use of capacity, and shortening of time cycle. Much of the total cost of caring for a patient involves shared resources, such as physicians, staff, facilities, and equipment. To measure the true costs, the cost of shared resources must be attributed to individual patients based on the actual resources used for their care, not on averages [5-7] (Fig. 1). 


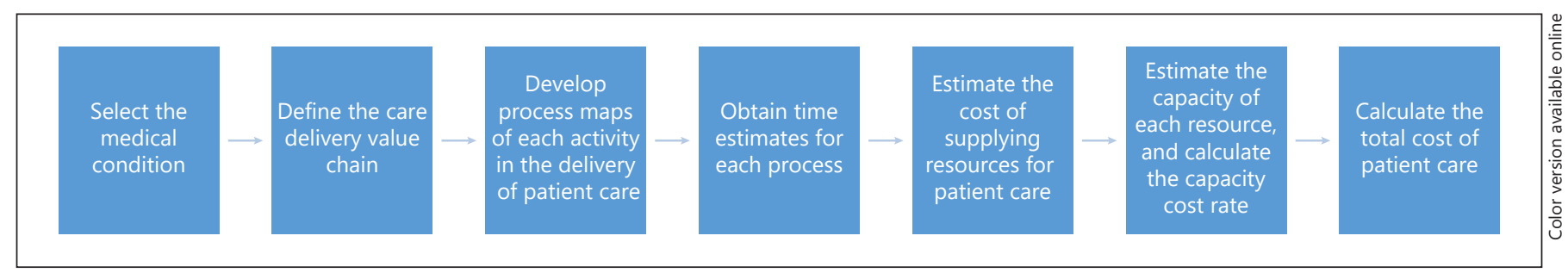

Fig. 1. The cost measurement process (based on Kaplan and Porter [7]).

We list here some of the main aspects of the Kaplan and Porter cost measurement process [7]. The first step is clinical identification. Here, it is crucial to define the cycle of care, which starts with prevention and finishes with disease management or follow-up. In the second stage, the main activities involved in each care cycle are determined, with the support of a multidisciplinary team (clinicians, nurses, accountants, and administrative staff). The third step is characterized by the conception of the process map for each value chain. This map permits the visualization of the alternatives in a health unit. The presence of the entire multidisciplinary team is essential to carry out this mapping process, and this team should determine which resources are necessary (space, staff, materials, and equipment) for each activity. The fourth step depicts the time estimated for each process. The manager should estimate the time that a user takes up for each resource at each stage of the process, thus identifying the duration of all activities. The fifth step is to determine the cost of all resources involved in the entire care cycle. The sixth step is to define the actual capacity of each resource, by subtracting from the theoretical capacity (i.e., that at which the resource would work at its full capacity) the estimated values for breaks, training, education, research, and other possible uses. Then, the capacity cost rate is computed, with the total cost incurred by the organization to make each resource available to the patient as the numerator and the estimated actual capacity as the denominator. Finally, the seventh step is the calculation of the total cost of patient care. This involves, first, the multiplication of the capacity cost rate by the time estimates for each activity. Then, the cost of a process is determined, which is the sum of all cost activities. Finally, the total cost of a care cycle for a given clinical condition is given by the sum of all process costs. Kaplan and Porter [7] presented a detailed description on how to measure costs.

This model proposes that value should be expressed as a function of the patient's initial conditions that affect the treatment processes, which, in turn, influence disease in- dicators that are eventually reflected in health outcomes. The key takeaway from this model is the opportunity to create and apply risk adjustments when assessing valuebased care [5-7, 59].

There is much to be said in favor of several aspects of this framework from a financial theory viewpoint, especially the realization that value measurement should not depend on single outcomes but should take into consideration all impacts of the decisions taken. However, it should also be stressed here that the ratio of outcomes-tocost does not measure value but is instead a measure of efficiency. Value, in finance and economics, is always expressed in monetary units, e.g., in euros and dollars, not in unitless ratios. Furthermore, when the healthcare evaluation is carried out, care should be taken to take the incremental nature of outcomes over time into account as well as the temporal distribution of costs, which should be estimated on a cash flow basis. Moreover, costs should be discounted at the appropriate rate.

\section{Conclusion}

Given the close relationship between human health and human life, the attempts to measure value in healthcare are fraught with conceptual difficulties and ethical problems. In practice, these problems can be overcome by either estimating the value of activities like work that health potentiates, or through revealed-preference methodologies.

The metrics used to determine value in healthcare methodologies analyzed above all seek to capture the preferences of individual patients in some way, even though, in practice, they are mostly used at a macro-level. The macro-level usage of these methods is partly explained by the difficulty of measuring individual preferences, which can change according to personal experiences and over time. The methodologies closest to health economics try to establish a link to measure value in terms 
of the labor units to facilitate measurement; on the other hand, more than any other method, the Porter framework makes use of cost accounting techniques, which are familiar to hospital administrators but place a heavy burden on information systems.

From a financial theory perspective, while cost-benefit analysis, CEA, and the Porter framework are able to present valuable insights, they do not reflect the modern concept of value and have several flaws. These include the measurement of costs according to accounting principles rather than on a cash flow basis, not taking the time value of money into consideration, and defining value as a ratio instead of measuring it in monetary units. Although all three metrics can be adapted to overcome these weaknesses, no such effort has yet been reported in the literature or is known to be taking place in actual practice. From a theoretical point of view, cost-utility analysis seems to be the most robust; however, serious methodological problems still make it difficult to apply in practice.

\section{Acknowledgement}

The authors are grateful to numerous colleagues who provided valuable feedback and constructive comments on previous versions of this paper presented at research seminars in several universities in Portugal, Taiwan, and Japan in 2019.

\section{Conflict of Interest Statement}

The authors have no conflicts of interest to declare.

\section{Funding Sources}

The authors declare that they did not receive any funding for this research.

\section{Author Contributions}

Both authors contributed jointly to the research and writing of this article.

\section{References}

1 Etges AP, Ruschel KB, Polanczyk CA, Urman $\mathrm{RD}$. Advances in value-based healthcare by the application of time-driven activity-based costing for inpatient management: a systematic review. Value Health. 2020 Jun;23(6): $812-23$.

2 Halm EA, Lee C, Chassin MR. Is volume related to outcome in health care? A systematic review and methodologic critique of the literature. Ann Intern Med. 2002 Sep;137(6): 511-20.

3 Lee TH. The word that shall not be spoken. N Engl J Med. 2013 Nov;369(19):1777-9.

4 Porter M, Lee R. The strategy that will fix health care. Harv Bus Rev. 2013;91(10):5070.

5 Porter ME. What is value in health care? $\mathrm{N}$ Engl J Med. 2010 Dec;363(26):2477-81.

6 Porter M, Teisberg EO. Redefining health care: creating value-based competition on results. Boston: Harvard Business Press; 2006.

7 Kaplan RS, Porter ME. How to solve the cost crisis in health care. Harv Bus Rev. 2011 Sep; 89(9):46-52.

8 Tai BB, Bae YH, Le QA. A systematic review of health economic evaluation studies using the patient's perspective. Value Health. 2016 Sep - Oct;19(6):903-8.

9 Lohr KN. Outcome measurement: concepts and questions. Inquiry. 1988;25(1):37-50.

10 van der Nat PB, van Veghel D, Daeter E, Crijns HJ, Koolen J, Houterman S, et al. Insights on value-based healthcare implementation from Dutch heart care. Int J Healthc Manag. 2017;13(3):189-92.
11 Myszewski J, Sinha MN. A model for determining the value of patient satisfaction in healthcare. Bus Process Manag J. 2019;26(3): 798-815.

12 Viney R, Lancsar E, Louviere J. Discrete choice experiments to measure consumer preferences for health and healthcare. Expert Rev Pharmacoecon Outcomes Res. 2002 Aug; 2(4):319-26.

13 Gray M. Value based healthcare. BMJ. 2017 Jan;356:j437.

14 Weston JF, Brigham EF. Managerial finance. 5th ed. Hinsdale: The Dryden Press; 1975.

15 Sharpe WF, Alexander GJ, Bailey JV. Investments. 6th ed. Upper Saddle River (NJ): Prentice Hall; 1999.

16 Ross S, Westerfield R, Jaffe J, Jordan B. Corporate finance. 12th ed. New York (NY): McGraw-Hill; 2019.

17 Brealey R, Meyers S, Allen F. Principles of corporate finance. 13th ed. New York (NY): McGraw-Hill; 2020.

18 Cameron D, Ubels J, Norström F. On what basis are medical cost-effectiveness thresholds set? Clashing opinions and an absence of data: a systematic review. Glob Health Action. 2018;11(1):1447828.

19 Moore MJ, Viscusi WK. The quantity-adjusted value of life. Econ Inq. 1988;26(3):369-88.

20 Galen. On the natural faculties. Brock A, translator. The Project Gutenberg e-book of On the Natural Faculties by Galen. London: William Heinemann; 1913. p. 163.
21 Weinstein MC, Torrance G, McGuire A. QALYs: the basics. Value Health. 2009 Mar;12(I Suppl 1):S5-9.

22 Plato. Laws (Jowett B, translator). The Dialogues of Plato. Chicago (IL): Encyclopaedia Britannica. 1978. p. 751.

23 Confucius (Waley A, translator). The Analects. London: Penguin Classics; 1998.

24 Mencius. Bloom I, transl. New York (NY): Columbia University Press; 2009.

25 Fukuzawa Y, editor. A message of farewell to Nakatsu. The thought of Fukuzawa: Fukuzawa Yukichi on women and the family. Tokyo: Keio University Press; 2017. pp. 3-63.

26 Boas F. Anthropology and Modern Life. New York (NY): Norton; 1962

27 Smith DL. Less than human: why we demean, enslave and exterminate others. New York (NY): St. Martin's Press; 2011.

28 Graeber D. Debt: the first 5.000 years. New York (NY): Melville House Publishing; 2011.

29 [Internet] World Health Organisation: basic documents [cited 2020 Feb 4]. Geneva: World Health Organisation; 2005. Available from: https://apps.who.int/iris/bitstream/handle/10665/121457/em_rc42_cwho_en.pdf

30 Lopes H, Mateus C, Hernández-Quevedo C. Ten years after the creation of the Portuguese national network for long-term care in 2006: achievements and challenges. Health Policy. 2018 Mar;122(3):210-6.

31 OCDE. Health at a glance: Europe 2018: state of health in the EU cycle. Paris: OECD Publishing; 2018. 
32 Goulart BH. Value: the next frontier in cancer care. Oncologist. 2016 Jun;21(6):651-3.

33 Schnipper LE, Davidson NE, Wollins DS, Tyne C, Blayney DW, Blum D, et al.; American Society of Clinical Oncology. American Society of Clinical Oncology Statement: a conceptual framework to assess the value of cancer treatment options. J Clin Oncol. 2015 Aug;33(23):2563-77.

34 Martin S, Rice N, Smith PC. Does health care spending improve health outcomes? Evidence from English programme budgeting data. J Health Econ. 2008 Jul;27(4):826-42.

35 Schumpeter JA. History of economic analysis. London: Allen \& Unwin; 1954.

36 Spiegel HW. The growth of economic thought. Durham: Duke University Press; 1991.

37 Rothbard MN. Economic thought before Adam Smith. Auburn: Ludwig von Mises Institute; 1995.

38 Fisher I. The theory of interest. New York (NY): Macmillan; 1930.

39 Adibe MO, Aguwa CN, Ukwe CV. Cost-utility analysis of pharmaceutical care intervention versus usual care in management of $\mathrm{Ni}$ gerian patients with type 2 diabetes. Value Health Reg Issues. 2013 Sep - Oct;2(2):18998.

40 Drummond M, O'Brien B, Stoddart G, Torrance $G$. Methods for the economic evaluation of health care programmes. 2nd ed. Oxford: Oxford University Press; 1997.

41 Torrance GW. Measurement of health state utilities for economic appraisal. J Health Econ. 1986 Mar;5(1):1-30.

42 Viscusi WK, Aldy JE. The value of a statistical life: a critical review of market estimates throughout the world. J Risk Uncertain. 2003; 27(1):5-76.
43 Arrow KJ. Uncertainty and the welfare economics of medical care. Am Econ Rev. 1963; 53(5):941-73.

44 Barros PP. Economia da saúde: conceitos e comportamentos. 3rd ed. Coimbra: Almedina; 2013.

45 Folland S, Goodman AC, Stano M. The economics of health and health care. 6th ed. Upper Saddle River (NJ): Prentice-Hall; 2009.

46 Hanley N, Ryan M, Wright R. Estimating the monetary value of health care: lessons from environmental economics. Health Econ. 2003 Jan;12(1):3-16.

47 Smith RD. Construction of the contingent valuation market in health care: a critical assessment. Health Econ. 2003 Aug;12(8):60928.

48 Smith RD. Contingent valuation in health care: does it matter how the 'good' is described? Health Econ. 2008 May; 17(5):60717.

49 Johannesson M, Jönsson B. Economic evaluation in health care: is there a role for costbenefit analysis? Health Policy. 1991 Feb; 17(1):1-23.

50 Grossman M. On the concept of health capital and the demand for health. J Polit Econ. 1972; 80(2):223-55.

51 Grossman M. The demand for health: a theoretical and empirical investigation. New York (NY): Columbia University Press; 1972.

52 Garrison LP Jr, Pauly MV, Willke RJ, Neumann PJ. An overview of value, perspective, and decision context: a health economics approach: an ISPOR Special Task Force Report [2]. Value Health. 2018 Feb;21(2):124-30.
53 Adibe MO, Aguwa CN, Ukwe CV. Cost-Utility Analysis of Pharmaceutical Care Intervention versus Usual Care in Management of Nigerian Patients with Type 2 Diabetes. Value Health Reg Issues. 2013;2(2):189-98.

54 Viney R, Lancsar E, Louviere J. Discrete choice experiments to measure consumer preferences for health and healthcare. Expert Rev Pharmacoecon Outcomes Res. 2002 Aug; 2(4):319-26.

55 Augustovski F, Colantonio LD, Galante J, Bardach A, Caporale JE, Zárate V, et al. Measuring the benefits of healthcare DALYs and QALYs: does the choice of measure matter? A case study of two preventive interventions. Int J Health Policy Manag. 2018 Feb;7(2):120-36.

56 Lakdawalla DN, Doshi JA, Garrison LP Jr, Phelps CE, Basu A, Danzon PM. Defining elements of value in health care: a health economics approach: an ISPOR Special Task Force report [3]. Value Health. 2018 Feb; 21(2):131-9.

57 Phelps CE, Lakdawalla DN, Basu A, Drummond MF, Towse A, Danzon PM. Approaches to aggregation and decision-making: a health economics approach: an ISPOR Special Task Force report [5]. Value Health. 2018 Feb;21(2):146-54.

58 Haas DA, Helmers RA, Rucci M, Brady M, Kaplan RS. The Mayo Clinic model for running a value-improvement program. Harv Bus Rev. 2015:1-3.

59 Kaplan RS, Witkowski M, Abbott M, Guzman AB, Higgins LD, Meara JG, et al. Using timedriven activity-based costing to identify value improvement opportunities in healthcare. Healthc Manag. 2014 Nov-Dec;59(6):399412 